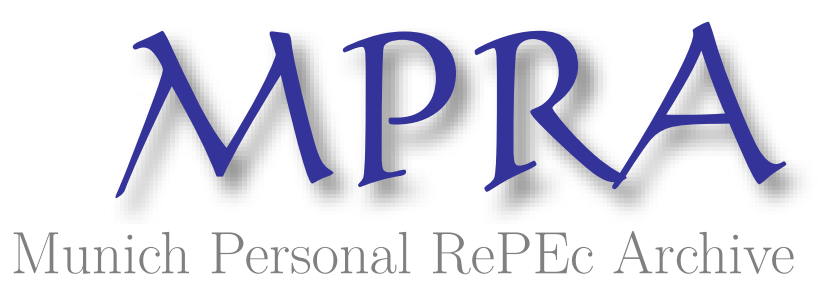

\title{
Measuring the effects of monetary policy in Pakistan: A factor augmented vector autoregressive approach
}

Munir, Kashif and Qayyum, Abdul

Pakistan Institute of Development Economics

16 January 2012

Online at https://mpra.ub.uni-muenchen.de/35976/

MPRA Paper No. 35976, posted 17 Jan 2012 07:05 UTC 


\title{
Measuring the Effects of Monetary Policy in Pakistan:
}

\section{A Factor Augmented Vector Autoregressive Approach}

\author{
Kashif Munir $^{* \dagger}$ and Abdul Qayyum ${ }^{*}$
}

\begin{abstract}
This paper examines the effects of monetary policy in Pakistan economy using a data rich environment. We used the Factor Augmented Vector Autoregressive (FAVAR) methodology, which contains 115 monthly variables for the period 1992:01 to 2010:12. We compare the results of VAR and FAVAR model and the results showed that FAVAR model explains the effects of monetary policy which are consistent with theory and better than VAR model. VAR model shows the existence of price puzzle and liquidity puzzle in Pakistan while FAVAR model did not provide any evidence of puzzles. FAVAR model supports the effectiveness of interest rate channel in Pakistan.
\end{abstract}

\footnotetext{
* This paper is a part of the author's Ph.D Dissertation.

$\dagger$ Author is a PhD economics student at Pakistan Institute of Development Economics, Islamabad, Pakistan. Corresponding author kashif@pide.org.pk

\$ Author is a Professor at Pakistan Institute of Development Economics, Islamabad, Pakistan.
} 


\section{Introduction}

Economic growth and price stability are the primary goals of macroeconomic policies and monetary policy is a tool to achieve the objective of economic growth and stable prices. Does monetary policy affect the real economy (economic activity)? If so, what is the transmission mechanism by which these effects occur? These two questions are among the most important and controversial in macroeconomics (Bernanke and Blinder 1992). Empirical estimation of the effects of monetary policy is another area of controversy among economists. Though now a consensus exist among economists that the long run effects of money fall entirely only on prices however the impact of monetary impulses on real variables in the short run is still open to debate (Walsh 2010). The short run interaction among the monetary variables and real variables is of vital importance for the conduct of monetary policy and demands thorough investigation.

The vector autoregressive (VAR) approach and the structural vector autoregressive (SVAR) approach have been the standard approaches employed in the monetary policy analysis since 1992 (Sims 1992; Bernanke and Blinder 1992). However, one of the major shortcomings of these standard VAR/SVAR models is that these are essentially low dimensional, i.e., the number of variables that can be included in the model is not too large i.e. usually less than 10 (Bernanke, Boivin and Eliasz 2005; Senbet, 2008; Blaes, 2009). Thus the VAR and SVAR models pose a major constraint to the analysis of monetary policy because the information sets used by monetary authorities for policy making literally extends to hundreds of variables.

The monetary policy regime and the financial sector of Pakistan underwent a considerable change in 1990, with primary focus on liberalization. Since then a number of policy changes 
have been made to move towards indirect and market-based monetary management ${ }^{4}$. The relative effectiveness of monetary policy has remained unexplored especially after the liberalization and restructuring of financial sector in Pakistan in 1990. Therefore there is a need to examine the extent of the effectiveness of the monetary policy in Pakistan and also to figure out the mechanism through which monetary policy shocks are transmitted to the economy.

To the best of our knowledge there are only few studies, focused on Pakistan, which measure the effects of monetary policy. Agha et al. (2005) used VAR to examine how shocks of monetary policy are transmitted to the real economy and conclude that bank lending is the most important channel of transmission in Pakistan. Khan (2008) estimate the impact of an unanticipated change in monetary policy on output and inflation using VAR and SVAR and conclude that transmission mechanism is much faster in case of consumer price index as compared to industrial production index. Hussain (2009) used VAR model to estimate the impact of monetary policy on inflation and output in Pakistan and concluded that exchange rate is a significant channel of monetary policy in controlling inflation and output. Javid and Munir (2011) employed SVAR model to measure the effects of monetary policy on prices, output, exchange rate and money supply and concluded that there is strong existence of price puzzle and exchange rate puzzle in Pakistan.

The studies that have analyzed the effects of monetary policy on macroeconomic variables in Pakistan have not used the FAVAR approach. An understanding of the effects of monetary policy on macroeconomic variables is crucial for the authorities to achieve the objectives of the policies i.e. high growth and stable prices. This study seeks to investigate the effects of monetary

\footnotetext{
${ }^{4}$ SBP (2002) Pakistan: Financial Sector Assessment 1990-2000.
} 
policy on macroeconomic variables in Pakistan by using the FAVAR methodology proposed by Bernanke, Boivin and Eliasz (2005).

The remainder of the study is organized in the following manner. Empirical literature on the effects of monetary policy is discussed in section 2. Methodology and data are described in section 3. The empirical results on the effects of monetary policy on macroeconomic variables are analyzed in section 4 . Section5 contains concluding remarks and policy recommendation.

\section{Empirical Literature}

After the pioneered work of Sims $(1980,1992)$ and Bernanke and Blinder (1992) Vector Autoregressive (VAR) model became the standard toolkit for the analysis of monetary policy. Sims (1992) measures the effects of monetary policy in France, Germany, Japan, UK and the US and used VAR model. He finds that a contractionary monetary policy (a positive shock in interest rate) leads to lower output and money, while consumer price index increases and called it as "price puzzle". Sims argues that this puzzling response of prices could be due to the fact that the central bankers have larger information sets than captured by four variables VAR. He included two more variables to the VAR model i.e. exchange rate (XR) and commodity price index (PC) and finds that the magnitude of prize puzzle decline with the inclusion of two more variables in the VAR. He concluded that an innovation in monetary policy is associated with lower economic activity and a reduction in monetary aggregates in all countries in the sample. Bernanke and Blinder (1992) measure the impact of monetary policy on real variables in the US and used VAR model. They find that monetary policy is best measured by innovation in the federal funds rate and monetary policy affects the real economic activity in the US and concluded that firstly, the funds rate is a good indicator of monetary policy, secondly, nominal interest rates are good forecast of real variables and lastly, monetary policy works in part by 
affecting the composition of bank assets. Peersman and Smets (2001) measure the macroeconomic effects of an unanticipated change in monetary policy in Euro area by using VAR model and concluded that a rise in the short term nominal interest rate leads to a real appreciation of the exchange rate with a fall in output, while prices shows sluggish behavior and fall significantly after several quarters. Miyao (2002) examine the effects of monetary policy on macroeconomic variables over the last two decades in Japan and used VAR model. He found that monetary policy shocks which are identified as call rate disturbances, have persistent effect on real output, especially in the rise and fall of Japan's bubble economy of the late 1980s.

Although VAR model became the standard toolkit to measure the effects of monetary policy but it has shortcomings and one of the major shortcomings of VAR models is that these are low dimensional i.e. the number of variables that can be included in the VAR model is not too large (Bernanke, Boivin and Eliasz 2005; Senbet 2008; Blaes 2009). Bernanke, Boivin and Eliasz (2005) argue that the sparse information set used by low dimensional VAR model leads to at least three potential problems

First, central banks or agents in the financial markets have larger information sets than the information set spanned by the variables in the VAR model, the measurement of policy shocks is most likely to be contaminated. This could be due to omitted variable bias inherent in the small scale VAR models (Breitung and Eickmeier 2005). One example of this policy contamination is the "price puzzle". The price puzzle is the usual finding in the VAR models in which prices increases in response to a contractionary monetary policy. One explanation given for the price puzzle is that the central banks have larger information set which is not captured by the VAR model (Sims 1992). 
Second, in VAR model, one has to take a stand on specific observable measures to represent some theoretical constructs. For example, one has to represent economic activity with a single series such as the gross domestic product, unemployment or industrial production. However, the concept of economic activity may not be well represented by a single series. It could be a reflection of a multiple macroeconomic series.

Third, in the standard VAR model, the impulse response functions can be observed only for those variables which are included in the model, which is generally a very small fraction of the variables that would interest the policymakers as well as researchers. To assess the impact of policy changes on economic activity, we might need to look at employment, sales, hourly earnings, weekly hours worked, changes in inventories, consumption of durable goods, capacity utilization and consumer confidence, in addition to the GDP or IP.

Based on the developments of dynamic factor models, Bernanke, Boivin and Eliasz (2005) come with an econometric methodology that solves the main shortcomings of the standard Vector Autoregressive (VAR) models and called it "Factor Augmented Vector Autoregressive (FAVAR)" model.

Bernanke, Boivin and Eliasz (2005) measure the effects of monetary policy on macroeconomic variables in the US. They used 120 monthly macroeconomic time series data from 1959 to 2003 and employed VAR and FAVAR model. They extract few common factors from the data and then use it with federal fund rate as policy variable in the FAVAR model and employed two methodologies to estimate the FAVAR i.e. two step principal component approach and Bayesian 
method based on Gibbs sampling. They compare the results of VAR and FAVAR model first and conclude that in FAVAR model there is no price puzzle and the response of output is according to the theory with an increase in federal funds rate, while VAR model shows strong price puzzle. They find that a contractionary monetary policy, measured by positive increase in the federal funds rate leads to a decline in industrial production, 3-month treasury bills, 5 year treasury bonds, monetary base, monetary aggregates (M2), commodity price index, capacity utilization rate, personal consumption, durable consumption, non-durable consumption, employment, housing starts, new orders, consumption of durable goods and consumer expectation, while prices initially rises and then decline. They conclude that both methods of estimation produce similar results, while two step approach produces more plausible results.

Lagana and Mountford (2005) study the impact of monetary policy on a number of macroeconomic variables in the UK and used VAR and FAVAR model. Their main findings are that a contractionary monetary policy is associated with a rise in housing prices and stock market prices, while it leads to a depreciation of UK pound to US dollar. They conclude that the addition of factors to VAR (FAVAR) model produces more superior results as compared to benchmark VAR model and AR models and it brings to light other identification issues such as house price and stock market puzzles. Shibamoto (2007) analyzes the monetary policy shocks on macroeconomic variables in Japan and used FAVAR model. There are three main findings, first, the time lags with which the monetary policy shocks are transmitted vary among various macroeconomic series, second, a coherent picture of the effects of monetary policy on the economy is obtained, and lastly, monetary policy shocks have strong impact on real variables i.e. employment and housing starts than industrial production. Carvalho and Junior (2009) analyze the effects of monetary policy in Brazilian economy and used FAVAR model. They find that 
with a contractionary monetary policy the variables used to measure economic activity responds negatively and their impact became null after few months which is consistent with long term neutrality of money and there is neither price puzzle nor liquidity puzzle existed in Brazil. They concluded that the results of VAR and FAVAR model have no change in the response of principal variables and the marginal contribution of information from factors is low in case of Brazil. Soares (2011) measures the effects of monetary policy in the Euro are in the period of single monetary policy and used FAVAR model. He finds that a contractionary monetary policy leads to a hump shaped pattern of GDP which is consistent with theory and the impulse response function obtained from FAVAR model are in line with the literature and make sense from an economic point of view, while comparing the results of FAVAR model with small scale VAR model, finds that the inclusion of the information captured by the factors mitigates the price puzzle. Kabundi and Ngwenya (2011) examine the effects of monetary policy on real, nominal and financial variables in South Africa and used FAVAR model. They find that with an increase in short term interest rate is associated negatively with production, utilization of productive capacity, disposable income, fixed investment, consumption expenditure and employment, the response of credit and M3 is also negative but start recovering after 24 months, while South African All Share Index (ALSI) respond negatively and quickly to monetary policy and recovers quickly too. They concluded that monetary policy is successful in affecting key macroeconomic variables, the effects are significant with expected signs as suggested by theory.

\subsection{Literature from Pakistan}

Agha et al. (2005) study the monetary transmission mechanism and the channels through which monetary shocks are transmitting in Pakistan and used VAR model. They find that with the 
tightening of monetary policy measured by increase in 6-month treasury bill rate the response of output is V-shaped and fully wiped out in one year, while prices did not decrease for six months which shows existence of strong price puzzle and lastly, bank lending channel is the most effective channel of monetary transmission mechanism in Pakistan. They concluded that monetary tightening leads to a decline in investment demand financed by bank lending which translates into a gradual reduction in price pressures and eventually reduces the overall price level with a significant lag. Khan (2008) analyzes the impact of monetary policy on macroeconomic variables i.e. IPI and CPI in Pakistan and used VAR and SVAR model. His main findings from VAR model are that an increase in money supply or reduction in 6-month treasury bills increases output and inflation in the short run, while SVAR model indicated that a positive nominal shock will increase output growth and inflation in the short run while, output shock dies out in 23 to 32 months and 70 to 90 percent increase in inflation is observed during 12 to 18 months. He concluded that transmission mechanism of monetary policy is much faster in consumer price index (CPI) as compared to industrial production index (IPI). Hussain (2009) estimate the impact of monetary policy on macroeconomic variables i.e. output and inflation in Pakistan and used VAR model. He concluded that exchange rate is a significant channel of monetary policy in controlling inflation and output as compared to interest rate and credit channel. Javid and Munir (2011) measure the effects of monetary policy on prices, output, exchange rate and money supply in Pakistan and used SVAR model. They find that a contractionary monetary policy is associated with increase in prices which did not decline in 48 months, while output initially rises and then decline continuously afterward. They concluded that there is strong existence of price puzzle and exchange rate puzzle in Pakistan. 
None of the above mentioned studies used FAVAR model to measure the effects of monetary policy in a data rich environment, from the above discussion we can conclude that there is a need to estimate the effects of monetary policy on macroeconomic variables in Pakistan in data rich environment.

\section{Methodology and Data}

Assume that there are $\mathrm{M}$ small number of observable economic variables that determine the dynamics of the economy contained in the vector $Y_{t}(M \times 1)$. However in many applications additional economic information not included in $Y_{t}$ may be relevant to model the dynamics of these series. Let $X_{t}(N \times 1)$ is a vector of economic time series which contain many stationary time series variables, $Y_{t}$ is a subset of $X_{t}$ and $N$ is a large number i.e. $N>>M$. Further assume that $X_{t}$ is compressed into a $K$ small number of unobserved factors $F_{t}(K \times 1)$ is a vector of unobserved factors that capture most of the information contained in $X_{t}$ and $N>>K$. The joint dynamics of $F_{t}$ and $Y_{t}$ can be represented by the following transition equation:

$$
\left[\begin{array}{c}
f_{1 t} \\
f_{2 t} \\
\vdots \\
f_{K t} \\
y_{1 t} \\
y_{2 t} \\
\vdots \\
y_{M t}
\end{array}\right]=\left[\begin{array}{cccc}
\Phi_{11}(L) & \Phi_{12}(L) & \cdots & \Phi_{1(K+M)}(L) \\
\Phi_{21}(L) & \Phi_{22}(L) & \cdots & \Phi_{2(K+M)}(L) \\
\vdots & \vdots & \ddots & \vdots \\
\Phi_{K 1}(L) & \Phi_{K 2}(L) & \cdots & \Phi_{K(K+M)}(L) \\
\vdots & \vdots & \ddots & \vdots \\
\Phi_{(K+M) 1}(L) & \Phi_{(K+M) 2}(L) & \cdots & \Phi_{(K+M)(K+M)}(L)
\end{array}\right]\left[\begin{array}{c}
f_{1 t} \\
f_{2 t} \\
\vdots \\
f_{K t} \\
y_{1 t} \\
y_{2 t} \\
\vdots \\
y_{M t}
\end{array}\right]+\left[\begin{array}{c}
u_{1 t} \\
u_{2 t} \\
\vdots \\
u_{K t} \\
\vdots \\
u_{(K+M) t}
\end{array}\right]
$$

or

$$
\left[\begin{array}{l}
F_{t} \\
Y_{t}
\end{array}\right]=\Phi(L)\left[\begin{array}{l}
F_{t} \\
Y_{t}
\end{array}\right]+U_{t}
$$


$\Phi^{*}(L)\left[\begin{array}{l}F_{t} \\ Y_{t}\end{array}\right]=U_{t}$

Where $\Phi^{*}(L)=I-\Phi(L), \Phi(L)=\Phi_{1} L+\cdots+\Phi_{p} L^{p}$ a matrix of conformable lag polynomial of finite order $\mathrm{p}$ in the lag operator $\mathrm{L}, \Phi_{j}(j=1,2, \ldots p)$, is a $((K+M) \times(K+M))$ matrix of coefficients and $U_{t}$ is $((K+M) \times 1)$ vector of error term with mean zero and covariance matrix $\Sigma_{U}$. Bernanke, Boivin and Eliasz (2005) calls equation (3.1) Factor Augmented Vector Autoregressive (FAVAR) model and interprets the unobserved factors as diffuse concepts such as economic activity or credit conditions which usually are represented by a large number of economic series i.e. $X_{t}$.

Since equation (3.1) cannot be estimated directly because the factors $F_{t}$ are unobservable. We can interpret the factors $F_{t}$ in addition to the observed variables $Y_{t}$ as the common forces which drives the dynamics of the economy. Assume that the relationship between the informational time series $\mathrm{X}_{t}$, the unobservable factors $F_{t}$ and the observed variables $Y_{t}$ is represented by an observation equation of the form:

$\left[\begin{array}{c}x_{1 t} \\ x_{2 t} \\ \vdots \\ x_{N t}\end{array}\right]=\left[\begin{array}{cccc}\Lambda^{f_{11}} & \Lambda^{f_{12}} & \cdots & \Lambda^{f_{1 K}} \\ \Lambda^{f_{21}} & \Lambda^{f_{22}} & \cdots & \Lambda^{f_{2 K}} \\ \vdots & \vdots & \ddots & \vdots \\ \Lambda^{f_{N 1}} & \Lambda^{f_{N 2}} & \cdots & \Lambda^{f_{N K}}\end{array}\right]\left[\begin{array}{c}f_{1 t} \\ f_{2 t} \\ \vdots \\ f_{K t}\end{array}\right]+\left[\begin{array}{cccc}\Lambda^{y_{11}} & \Lambda^{y_{12}} & \cdots & \Lambda^{y_{1 M}} \\ \Lambda^{y_{21}} & \Lambda^{y_{22}} & \cdots & \Lambda^{y_{2 M}} \\ \vdots & \vdots & \ddots & \vdots \\ \Lambda^{y_{N 1}} & \Lambda^{y_{N 2}} & \cdots & \Lambda^{y_{N M}}\end{array}\right]\left[\begin{array}{c}y_{1 t} \\ y_{2 t} \\ \vdots \\ y_{M t}\end{array}\right]+\left[\begin{array}{c}e_{1 t} \\ e_{2 t} \\ \vdots \\ e_{N t}\end{array}\right]$
or
$X_{t}=\Lambda^{f} F_{t}+\Lambda^{y^{y}} Y_{t}+E_{t}$ 
Where $K+M<<N, F_{t}$ is a $K \times 1$ vector containing $K$ unobserved factors, $\Lambda^{f}$ is a $N \times K$ matrix of factor loadings, $\Lambda^{y}$ is a $N \times M$ matrix of coefficients and $E_{t}$ is a $N \times 1$ vector of error terms with mean zero and covariance matrix $\Sigma_{E}$ which are weakly correlated. Equation (3.2) is called the observation equation, and captures the idea that both $Y_{t}$ and $F_{t}$ represent forces that drive the common dynamics of $X_{t}$. Moreover, conditional on $Y_{t}$ the $X_{t}$ are noisy measures of the underlying unobserved factors $F_{t}$. Stock and Watson (2002) refer to equation (3.2) without observable factors as the dynamic factor model.

It can be seen that equation (3.1) is just a VAR in $F_{t}$ and $Y_{t}$, which nests the standard VAR model if the term $\Phi(L)$ that relate $Y_{t}$ to $F_{t}$ are all zero. If the true system that describes the dynamics of the economy is FAVAR, then estimating it as standard VAR will involve an omitted variable bias because of the omission of the factors. As a consequence the estimated VAR coefficient and everything that depends on them will be biased.

\subsection{Estimation}

Equation (3.1) can be estimated as a standard $\mathrm{VAR}^{5}$ if $F_{t}$ is observed, but this is not possible because factors $F_{t}$ are unobservable. To estimate the FAVAR model (3.1) - (3.2) we follow the two step principal component approach. This approach provides a non-parametric way of uncovering the space spanned by the common components $C_{t}=\left(F_{t}, Y_{t}\right)$ in equation (3.2). Another feature of principal components is that it permits one to deal systematically with data irregularities, Bernanke and Boivin (2003) estimate factors in the case in which $X_{t}$ may include

\footnotetext{
${ }^{5}$ See Hamilton (1994) and Lutkepohl (2005) for estimation of VAR model.
} 
both monthly and quarterly series as well as the series that are introduced during the data span or discontinued or have missing values.

In the first step the common components $C_{t}$ are estimated using the first $K+M$ principal components of $X_{t}$. The first step of the estimation does not exploit the fact that $Y_{t}$ is observed. However $\hat{F}_{t}$ is obtained as the part of the space covered by $\hat{C}_{t}$ which is not covered by $Y_{t}$. In the second step the FAVAR equation (3.1) is estimated by ordinary least squares (OLS), $F_{t}$ replacing by $\hat{F}_{t}$. It imposes few distributional assumptions and allows for some degree of cross correlation in the idiosyncratic error term $E_{t}$ (Stock and Watson 2002). However given that the factors are unobserved and what we actually use are estimated factors, it is necessary to estimate standard errors using bootstrap procedure, to obtain accurate confidence intervals on the impulse response. Therefore we implement the bootstrap procedure based on Kilian (1998) that accounts for the uncertainty in the factor estimation.

The discount rate ${ }^{6}$ is the monetary policy instrument in Pakistan. Therefore the innovation in the discount rate can be interpreted as monetary policy shocks. Following Bernanke, Boivin and Eliasz (2005) we use discount rate (monetary policy instrument in Pakistan i.e. $R_{t}$ ) as observable (only variable in the vector $Y_{t}$ i.e. $Y_{t}=R_{t}$ ), and all other variables as unobservable. We use a recursive procedure to identify monetary policy shocks, all the factors entering equation (3.1) respond with a lag to change in the monetary policy instrument, which is ordered last in the FAVAR.

\footnotetext{
${ }^{6}$ Discount rate is the officially announced instrument of monetary policy in Pakistan. Even though there is not much variation in it, but at monthly frequency it has sufficient variation to capture the dynamics of the monetary policy in Pakistan.
} 


\subsubsection{Identification of the Factors}

Under the recursive assumption about $\left[F_{t}, R_{t}\right]$ we need an intermediate step to obtain the final estimated factors $\hat{F}_{t}$, that will enter the FAVAR equation. As $K+M$ principal components estimated from the whole data set $X$, denoted by $\hat{C}\left(F_{t}, R_{t}\right)$, allow us to consistently recover $K+M$ independent but arbitrary linear combinations of $F_{t}$ and $\mathrm{R}_{t}$ given the observation equation (3.2). Since $\mathrm{R}_{t}$ is not imposed as an observable component in the first stage, any of the linear combinations underlying $\hat{C}\left(F_{t}, R_{t}\right)$ could involve the monetary policy instrument $R_{t}$. Thus it would not be valid to estimate a VAR in $\hat{C}\left(F_{t}, R_{t}\right)$ and $\mathrm{R}_{t}$ and to identify the policy shock recursively. Therefore first we have to remove the dependence of $\hat{C}\left(F_{t}, R_{t}\right)$ on $R_{t}$ and obtain the final estimated factor $\hat{F}_{t}$.

To obtain the factors free from the policy instrument effect Bernanke, Boivin and Eliasz (2005) procedure is followed. The matrix $X_{t}$ is divided in slow moving and fast moving variables. Slow moving variables are those which respond with lags after a shock in monetary policy and include production, prices and etc. While fast moving variables are contemporaneously responsive to monetary policy, these are highly sensitive to policy shocks and news such as interest rate, financial assets and exchange rate. Appendix A classifies variables into slow moving and fast moving.

To remove the dependence of $\hat{C}\left(F_{t}, R_{t}\right)$ on $R_{t}$, we have to obtain $\hat{C}^{*}\left(F_{t}\right)$ as an estimate of all the common components other than $R_{t}$. As slow moving variables are affected after lags by $R_{t}$, therefore $\hat{C}^{*}\left(F_{t}\right)$ is obtained by extracting principal components from the set of variables which are categorized as slow moving variables. The estimated common components $\hat{C}\left(F_{t}, R_{t}\right)$ are regressed on the estimated slow moving factors $\hat{C}^{*}\left(F_{t}\right)$ and on the observed variables $R_{t}$ as: 
$\hat{C}\left(F_{t}, R_{t}\right)=b_{C^{*}} \hat{C}^{*}\left(F_{t}\right)+b_{R} R_{t}+\tau_{t}$

And finally $\widehat{F}_{t}$ is estimated as

$\hat{F}_{t}=\hat{C}\left(F_{t} R_{t}\right)-\hat{b}_{R} R_{t}$

And the VAR in $\widehat{F}_{t}$ and $\mathrm{R}_{\mathrm{t}}$ is estimated as:

$\left[\begin{array}{c}\hat{f}_{1 t} \\ \hat{f}_{2 t} \\ \vdots \\ \hat{f}_{K t} \\ r_{t}\end{array}\right]=\left[\begin{array}{cccc}\widehat{\Psi}_{11}(L) & \widehat{\Psi}_{12}(L) & \cdots & \widehat{\Psi}_{1(K+1)}(L) \\ \widehat{\Psi}_{21}(L) & \widehat{\Psi}_{22}(L) & \cdots & \widehat{\Psi}_{2(K+1)}(L) \\ \vdots & \vdots & \ddots & \vdots \\ \widehat{\Psi}_{K 1}(L) & \widehat{\Psi}_{K 2}(L) & \cdots & \widehat{\Psi}_{K(K+1)}(L) \\ \widehat{\Psi}_{(K+1) 1}(L) & \widehat{\Psi}_{(K+1) 2}(L) & \cdots & \widehat{\Psi}_{(K+1)(K+1)}(L)\end{array}\right]\left[\begin{array}{c}\hat{f}_{1 t} \\ \hat{f}_{2 t} \\ \vdots \\ \hat{f}_{K t} \\ r_{t}\end{array}\right]+\left[\begin{array}{c}\varepsilon_{\hat{f}_{1 t}} \\ \varepsilon_{\hat{f}_{2 t}} \\ \vdots \\ \varepsilon_{\hat{f}_{K t}} \\ \varepsilon_{r_{t}}\end{array}\right]$

or

$\left[\begin{array}{l}\hat{F}_{t} \\ R_{t}\end{array}\right]=\widehat{\Psi}(L)\left[\begin{array}{l}\hat{F}_{t} \\ R_{t}\end{array}\right]+\epsilon_{t}$

or

$\widehat{\Psi}^{*}(L)\left[\begin{array}{l}\widehat{F}_{t} \\ R_{t}\end{array}\right]=\epsilon_{t}$

Where $\widehat{\Psi}^{*}(L)=I-\widehat{\Psi}(L), \widehat{\Psi}(L)=\widehat{\Psi}_{1} \mathrm{~L}+\cdots+\widehat{\Psi}_{\mathrm{p}} \mathrm{L}^{\mathrm{p}}$ a matrix of conformable lag polynomial of finite order $\mathrm{p}$ in the lag operator $\mathrm{L}, \widehat{\Psi}_{\mathrm{j}}(j=1,2, \ldots p)$ is a $((K+1) \times(K+1))$ coefficient matrix and $\epsilon_{t}$ is a $((K+1) \times 1)$ vector of structural innovations within the diagonal covariance matrix. 


\subsubsection{Identification of the VAR}

To identify the macroeconomic shock we are assuming a recursive structure, where the factors entering equation (3.5) respond with a lag (i.e. do not respond within the same period - a month here) to an unanticipated change in monetary policy instrument.

The recursiveness assumption makes use of the Cholesky Decomposition ${ }^{7}$ of the variance covariance matrix of the estimated residuals; a simple algorithm for splitting a symmetric positive definite matrix into a lower triangular matrix multiplied by its transpose. The Cholesky Decomposition implies a strict causal ordering of the variables in the VAR. The variables ordered last responds contemporaneously to all the others, while none of these variables respond contemporaneously to the variable ordered last. The next to last variable responds contemporaneously to all variables except the last, whereas only the last variable responds contemporaneously to it. An identification assumption in VAR studies of the monetary transmission mechanism is that monetary policy shock is orthogonal to the variables in the policy rule, in the sense that economic variables in the central bank's information set do not respond contemporaneously to the realizations of the monetary policy shock. This implies that some variables are exogenous to the policy shock. We follow the Cholesky Decomposition scheme in which the policy variable i.e. discount rate, is ordered last and treat its innovations as the policy shocks.

\footnotetext{
${ }^{7}$ The Cholesky Decomposition implies short run restrictions on the error term of the VAR model. This is a standard assumption in monetary policy analysis which enables transformation of the errors of the reduced form of the VAR model into structural innovations. This procedure is well explained in Bagliano and Favero (1998), Christiano, Eichenbaum and Evans (1999) and Gerke and Werner (2001).
} 


\subsubsection{Number of Factors and Lag Selection}

The literature on multivariate analysis proposes several criteria for determining the appropriate number of factors, many empirical studies adopt the method proposed in Bai and $\mathrm{Ng}$ (2002). But none of these criteria consider that the factor will be included in the VAR and therefore restrictions are imposed due to the loss of degree of freedom. We have estimated the VAR model using one factor $(K=1)$ and three factors $(K=3)$, while we estimate the corresponding FAVAR model with three factors $(\mathrm{K}=3)$ and five factors $(\mathrm{K}=5)$ to compare the results.

The results are robust to the use of more than five factors. Therefore the FAVAR model with five factors is our benchmark model. We compare results obtained from three and five factors FAVAR models, to demonstrate that how the inclusion of factors (i.e. information) can improve the results.

For the lag selection of VAR model we use likelihood ratio (LR) test. Since error terms are weakly correlated in equation (3.2), therefore the autocorrelation is not eliminated even with the inclusion of lags. As we are using monthly data so to include 12 lags is appropriate to encounter autocorrelation (i.e. $\mathrm{p}=12$ ); because if at 12 lags autocorrelation does not eliminate, it minimizes the problem of autocorrelation.

\subsubsection{Impulse Response Function}

A VAR or FAVAR model consists of a large number of parameters and thus it is difficult to identify the dynamic interaction between the variables. It is of advantage to estimate the impulse response function (IRF), where the dynamic effects are illustrated graphically. The impulse response function shows the dynamic effect of a structural shock on macroeconomic variables. 
All stationary VAR (p) models can be illustrated as Moving Average (MA) process of infinite order $(\operatorname{MA}(\infty))$, where the current values of the variables are weighted average of all historical innovations. The impulse response of the estimated factors and of the variables observed included in $Y_{t}$ can be computed from equation (3.5) as:

$\widehat{\Psi}^{*}(L)\left[\begin{array}{c}\hat{f}_{1 t} \\ \hat{f}_{2 t} \\ \vdots \\ \hat{f}_{K t} \\ r_{t}\end{array}\right]=\left[\begin{array}{c}\varepsilon_{\hat{f}_{1 t}} \\ \varepsilon_{\hat{f}_{2 t}} \\ \vdots \\ \varepsilon_{\hat{f}_{K t}} \\ \varepsilon_{r_{t}}\end{array}\right]$

The $\mathrm{MA}(\infty)$ representation is used to estimate the dynamic effects as follows:

$\left[\begin{array}{c}\hat{f}_{1 t} \\ \hat{f}_{2 t} \\ \vdots \\ \hat{f}_{K t} \\ r_{t}\end{array}\right]=\left[\widehat{\Psi}^{*}(L)\right]^{-1}\left[\begin{array}{c}\varepsilon_{\hat{f}_{1 t}} \\ \varepsilon_{\hat{f}_{2 t}} \\ \vdots \\ \varepsilon_{\hat{f}_{K t}} \\ \varepsilon_{r_{t}}\end{array}\right]$

or

$\left[\begin{array}{c}\hat{F}_{t} \\ R_{t}\end{array}\right]=\left[\widehat{\Psi}^{*}(L)\right]^{-1} \epsilon_{t}$

We can write it as:

$\left[\begin{array}{l}\hat{F}_{t} \\ R_{t}\end{array}\right]=\sum_{j=0}^{\infty} \hat{\Theta}_{j} L^{j} \epsilon_{t}=\sum_{j=0}^{\infty} \widehat{\Theta}_{j} \epsilon_{t-j}$

Where, $\sum_{j=0}^{\infty} \widehat{\Theta}_{j} L^{j}=\left[\widehat{\Psi}^{*}(L)\right]^{-1}$ 
By using the estimator of $X_{t}$ in equation (3.2)

$$
\begin{aligned}
& {\left[\begin{array}{c}
\hat{x}_{1 t} \\
\hat{x}_{2 t} \\
\vdots \\
\hat{x}_{N t}
\end{array}\right]=\left[\begin{array}{cccc}
\hat{\Lambda}^{f_{11}} & \hat{\Lambda}^{f_{12}} & \cdots & \hat{\Lambda}^{f_{1 K}} \\
\hat{\Lambda}^{f_{21}} & \hat{\Lambda}^{f_{22}} & \cdots & \hat{\Lambda}^{f_{2 K}} \\
\vdots & \vdots & \ddots & \vdots \\
\hat{\Lambda}^{f_{N 1}} & \hat{\Lambda}^{f_{N 2}} & \cdots & \hat{\Lambda}^{f_{N K}}
\end{array}\right]\left[\begin{array}{c}
\hat{f}_{1 t} \\
\hat{f}_{2 t} \\
\vdots \\
\hat{f}_{K t}
\end{array}\right]+\left[\begin{array}{cccc}
\hat{\Lambda}^{y_{11}} & \hat{\Lambda}^{y_{12}} & \cdots & \hat{\Lambda}^{y_{1 M}} \\
\hat{\Lambda}^{y_{21}} & \hat{\Lambda}^{y_{22}} & \cdots & \hat{\Lambda}^{y_{2 M}} \\
\vdots & \vdots & \ddots & \vdots \\
\hat{\Lambda}^{y_{N 1}} & \hat{\Lambda}^{y_{N 2}} & \cdots & \hat{\Lambda}^{y_{N M}}
\end{array}\right]\left[\begin{array}{c}
y_{1 t} \\
y_{2 t} \\
\vdots \\
y_{M t}
\end{array}\right]} \\
& \text { or } \\
& \hat{X}_{t}=\hat{\Lambda}^{f} \hat{F}_{t}+\hat{\Lambda}^{y} Y_{t}
\end{aligned}
$$

More specifically we can write equation (3.8) as:

$$
\begin{aligned}
& {\left[\begin{array}{c}
\hat{x}_{1 t} \\
\hat{x}_{2 t} \\
\vdots \\
\hat{x}_{N t}
\end{array}\right]=\left[\begin{array}{cccc}
\hat{\Lambda}^{f_{11}} & \hat{\Lambda}^{f_{12}} & \cdots & \hat{\Lambda}^{f_{1 K}} \\
\hat{\Lambda}^{f_{21}} & \hat{\Lambda}^{f_{22}} & \cdots & \hat{\Lambda}^{f_{2 K}} \\
\vdots & \vdots & \ddots & \vdots \\
\hat{\Lambda}^{f_{N 1}} & \hat{\Lambda}^{f_{N 2}} & \cdots & \hat{\Lambda}^{f_{N K}}
\end{array}\right]\left[\begin{array}{c}
\hat{f}_{1 t} \\
\hat{f}_{2 t} \\
\vdots \\
\hat{f}_{K t}
\end{array}\right]+\left[\begin{array}{c}
\hat{\Lambda}^{r_{1}} \\
\hat{\Lambda}^{r_{2}} \\
\vdots \\
\hat{\Lambda}^{r_{N}}
\end{array}\right]\left[r_{t}\right]} \\
& \text { or } \\
& \hat{X}_{t}=\hat{\Lambda}^{f} \hat{F}_{t}+\hat{\Lambda}^{r} R_{t}
\end{aligned}
$$

We can compute the impulse response function of each variable included in $X_{t}$ by using the equation (3.7) and (3.9) as:

$\left[\begin{array}{c}\hat{x}_{1 t} \\ \hat{x}_{2 t} \\ \vdots \\ \hat{x}_{N t}\end{array}\right]=\left[\begin{array}{ccccc}\hat{\Lambda}^{f_{11}} & \hat{\Lambda}^{f_{12}} & \cdots & \hat{\Lambda}^{f_{1 K}} & \hat{\Lambda}^{r_{1}} \\ \hat{\Lambda}^{f_{21}} & \hat{\Lambda}^{f_{22}} & \cdots & \hat{\Lambda}^{f_{2 K}} & \hat{\Lambda}^{r_{2}} \\ \vdots & \vdots & \ddots & \vdots & \vdots \\ \hat{\Lambda}^{f_{N 1}} & \hat{\Lambda}^{f_{N 2}} & \cdots & \hat{\Lambda}^{f_{N K}} & \hat{\Lambda}^{r_{N}}\end{array}\right]\left[\begin{array}{c}\hat{f}_{1 t} \\ \hat{f}_{2 t} \\ \vdots \\ \hat{f}_{K t} \\ r_{t}\end{array}\right]$

or 
$\hat{X}_{t}=\left[\begin{array}{ll}\widehat{\Lambda}^{\mathrm{f}} & \widehat{\Lambda}^{\mathrm{r}}\end{array}\right]\left[\begin{array}{l}\hat{F}_{t} \\ R_{t}\end{array}\right]$

Using the equation (3.7) we get the impulse response function of each variable included in $X_{t}$ as:

$\left[\begin{array}{c}x_{1 t}^{i r f} \\ x_{2 t}^{i r f} \\ \vdots \\ x_{N t}^{i r f}\end{array}\right]=\left[\begin{array}{ccccc}\hat{\Lambda}^{f_{11}} & \hat{\Lambda}^{f_{12}} & \cdots & \hat{\Lambda}^{f_{1 K}} & \hat{\Lambda}^{r_{1}} \\ \hat{\Lambda}^{f_{21}} & \hat{\Lambda}^{f_{22}} & \cdots & \hat{\Lambda}^{f_{2 K}} & \hat{\Lambda}^{r_{2}} \\ \vdots & \vdots & \ddots & \vdots & \vdots \\ \hat{\Lambda}^{f_{N 1}} & \hat{\Lambda}^{f_{N 2}} & \cdots & \hat{\Lambda}^{f_{N K}} & \hat{\Lambda}^{r_{N}}\end{array}\right] \sum_{j=0}^{\infty} \hat{\Theta}_{j} \epsilon_{t-j}$

or

$X_{t}^{I R F}=\left[\begin{array}{ll}\widehat{\Lambda}^{\mathrm{f}} & \widehat{\Lambda}^{\mathrm{r}}\end{array}\right] \sum_{j=0}^{\infty} \hat{\Theta}_{j} \epsilon_{t-j}$

\subsection{Data}

Our data set consists of 115 monthly macroeconomic time series for Pakistan. The data sources include State Bank of Pakistan, Pakistan Bureau of Statistics and International Financial Statistics (IFS). The data span is January 1992 to December 2010 and the frequency is monthly. The choice of the starting point of the data span has been choosen to reflect the time when the liberalization of monetary regime began in Pakistan.

In Pakistan there are many data limitations which we have to consider before proceeding further. The GDP is available at annual frequency only, so we have to use some proxy for GDP i.e. industrial production index which is available at monthly frequency. Data on employment and unemployment is also available at annual frequency only with many missing values, so we did not include data on employment in the study. To capture the effects of monetary policy on 
capital market we have used State Bank General Index and Sensitive Index of stock prices. However the State Bank of Pakistan has discontinued the construction of index since June 2008, having no other substitute of that data, we have used State Bank General Index and Sensitive Index of stock prices. The values from July 2008 to December 2010 are consider missing values and have been taken care of using principal component analysis.

The data has been processed in four different stages as follows:

First, as seasonal patterns are often large enough to hide data characteristics of interest, the series are seasonally adjusted. As we are using data at monthly frequency, seasonality is possible in all the macroeconomic time series. The seasonal effects of the series were estimated and removed. The approach used relies on a multiplicative decomposition through X-12 ARIMA, for all positive series and on additive decomposition for the remaining series. Appendix A describe whether a series is seasonally adjusted or not.

Second, we have transformed the series to achieve linearity and stability of the variance. We performed logarithmic transformation to a series to achieve linearity of the data. As majority of the economic series show exponential growth, therefore logarithmic transformation best suited to secure linearity. The decision whether to transform or not to transform the series depends on the characteristics of the data series. If the series has large variance, it is transformed otherwise not. The transformation of individual series is described in Appendix A.

Third, as indicated earlier, it is assumed that all the variables included in $X_{t}$ are stationary. Therefore all the variables are subject to unit root test. We have used Augmented Dicky Fuller test to check the stationarity of the series. The non-stationary 
series have been made stationary by taking their first or second difference, whichever is appropriate to make a series stationary.

Finally, since all the macroeconomic time series are on different units and scales this can impair factor extraction. To overcome this problem, all the informational series used to compute the factors were standardized to have mean zero and unit variance. The VAR and FAVAR estimation was conducted using non-standardized variables.

The steps discussed above have been followed in the same order in which these have been described.

\section{Results}

We begin by comparing the results of VAR model and FAVAR model. The FAVAR model which we specify in section 3 reduces to standard VAR model if we assume that all $\Phi(L)=O$ in equation (3.1) which relates $Y_{t}$ to $F_{t}$. Our baseline VAR model includes four variables (i.e. IPI, CPIG, M2 and DISR) in Cholesky ordering. The benchmark FAVAR model includes policy variables, five factors and the variable of interest (i.e. IPI, CPIG, M2 and DISR). To get a more clear picture, we compare baseline VAR model with the benchmark FAVAR model and then include one and three factors in the VAR model to see whether the inclusion of factors (information) improves the results of VAR model or not. To this end, the following four models are used for comparison:

i. Benchmark FAVAR model ( $\mathrm{Y}=\mathrm{DISR}$ and $\mathrm{K}=5$ )

ii. Baseline VAR model (Y=IPI, CPIG, M2, DISR and $\mathrm{K}=0$ )

iii. VAR model with one factor (Y=IPI, CPIG, M2, DISR and $\mathrm{K}=1$ )

iv. VAR model with three factors (Y=IPI, CPIG, M2, DISR and $\mathrm{K}=3$ ) 
Figure 4.1 to 4.4 shows the impulse response functions of benchmark FAVAR model and baseline VAR model with alternative specifications of FAVAR model. To examine the response of IPI, CPIG, M2 and DISR, we gave a 50 basis point positive shock to the discount rate.

Figure 4.1 shows the impulse response function of a 50bp positive shock in discount rate on discount rate, as it can be seen from the figure 4.1 that the benchmark FAVAR model shows more reliable results as compared to the baseline VAR model. In baseline VAR model discount rate reflects its own shock and takes more than 48 months to die which is inconsistent with the theory, when we include one factor and three factors our result improves, with one factor the results shows less consistency, while with three factors it shows much more consistency and the shock takes 28 months to die. In the preferred benchmark FAVAR model impulse response of discount rate is consistent with the theory and dies after 20 months. Similar results are reported by Bernanke, Boivin and Eliasz (2005), Soares (2011) and Lagana and Andrew (2005).

Figure 4.1: Impulse response of a 50bp shock in discount rate on Discount Rate

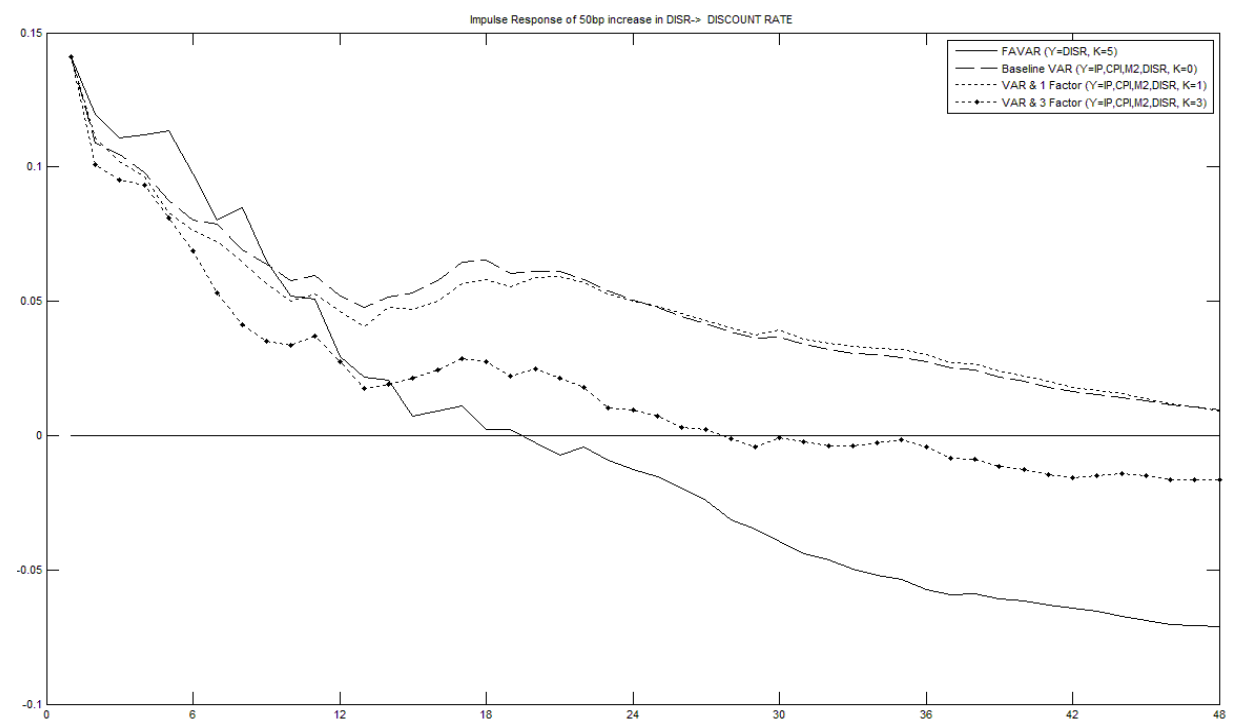

Figure 4.2 shows the impulse response function of a 50bp positive shock in discount rate on economic activity i.e. Industrial Production Index (IPI). In the benchmark FAVAR model, after 
the shock IPI shows declining trend and after 6 months it shows reviving trend. On the other hand, baseline VAR model indicate that IPI shows cyclical movements up to 13 months and then keep declining and shows no sign of convergence. Based on these results we can say that resultsof baseline VAR model are not consistent with the theory which describes a hump shape behavior of output and neutrality of money in the long run. When we include one factor and three factors this would improve our results and shows the non-neutrality of money in Pakistan. However, the benchmark FAVAR model shows that the results are consistent with the theory which says that output follows a hump shape behavior and converge as the effects of the shocks fade out after 44 months. The benchmark FAVAR model favors the long run neutrality of money in Pakistan which implies monetary policy did not exerts any effect on real variables i.e. output in the long run in Pakistan.

Figure 4.2: Impulse response of a 50bp shock in discount rate on Industrial Production Index

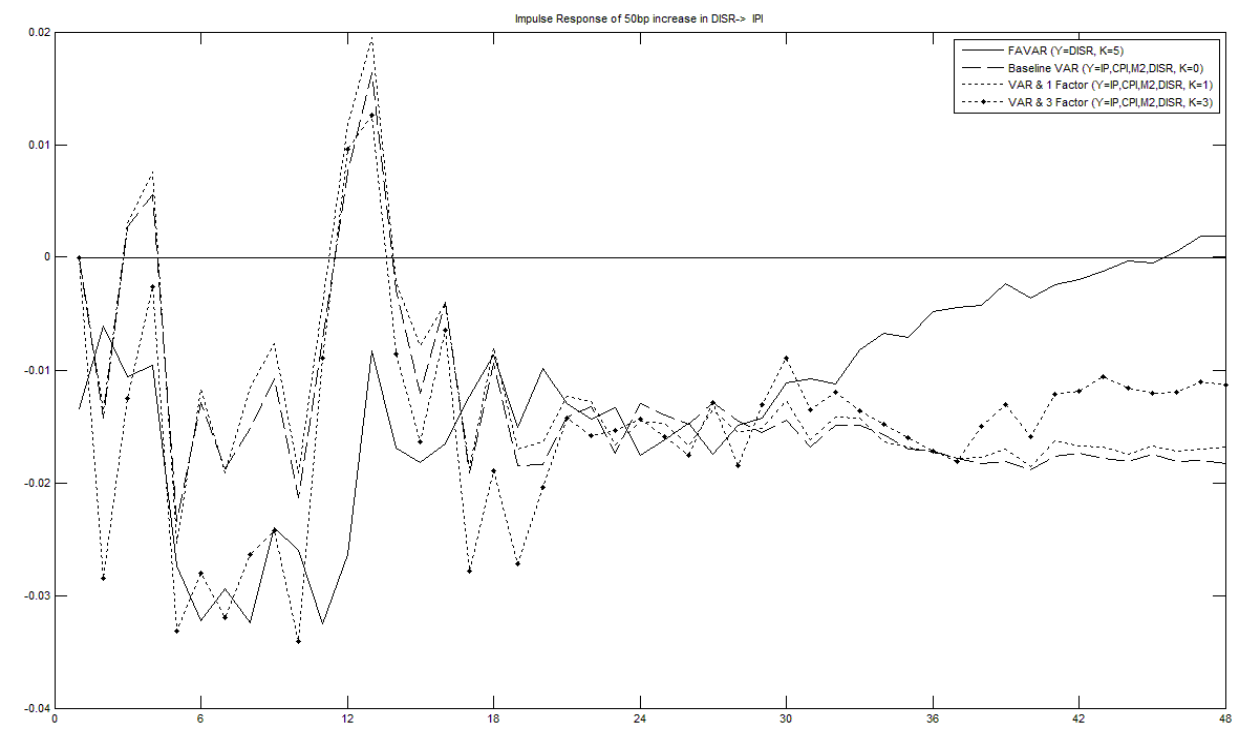

Figure 4.3 shows the impulse response function of a $50 \mathrm{bp}$ positive shock in discount rate on CPI. The benchmark FAVAR model shows that after a 50bp shock the CPI initially shows no response, however after 4 months CPI is persistently declining and showing no sign of price 
puzzle in Pakistan. On the other hand the baseline VAR model shows strong existence of price puzzle in Pakistan, with the tightening of monetary policy, prices increases in Pakistan and takes 40 months to decline. The existence of price puzzle in Pakistan is also reported by Agha et al. (2005), Khan (2008) and Javid and Munir (2010). But as we include one factor and three factors in the VAR model, the existence of price puzzle weakened with every addition of a factor. So, the inclusion of factors in the VAR model improves our results and weakens the existence price puzzle. The benchmark FAVAR model shows the results which are consistent with the theory, a positive shock in monetary policy innovation decrease prices but takes 5 months to affect the prices. In Pakistan prices are flexible as compared to output and transmission of monetary policy to prices is faster than output.

Figure 4.3: Impulse response of a 50bp shock in discount rate on Consumer Price Index

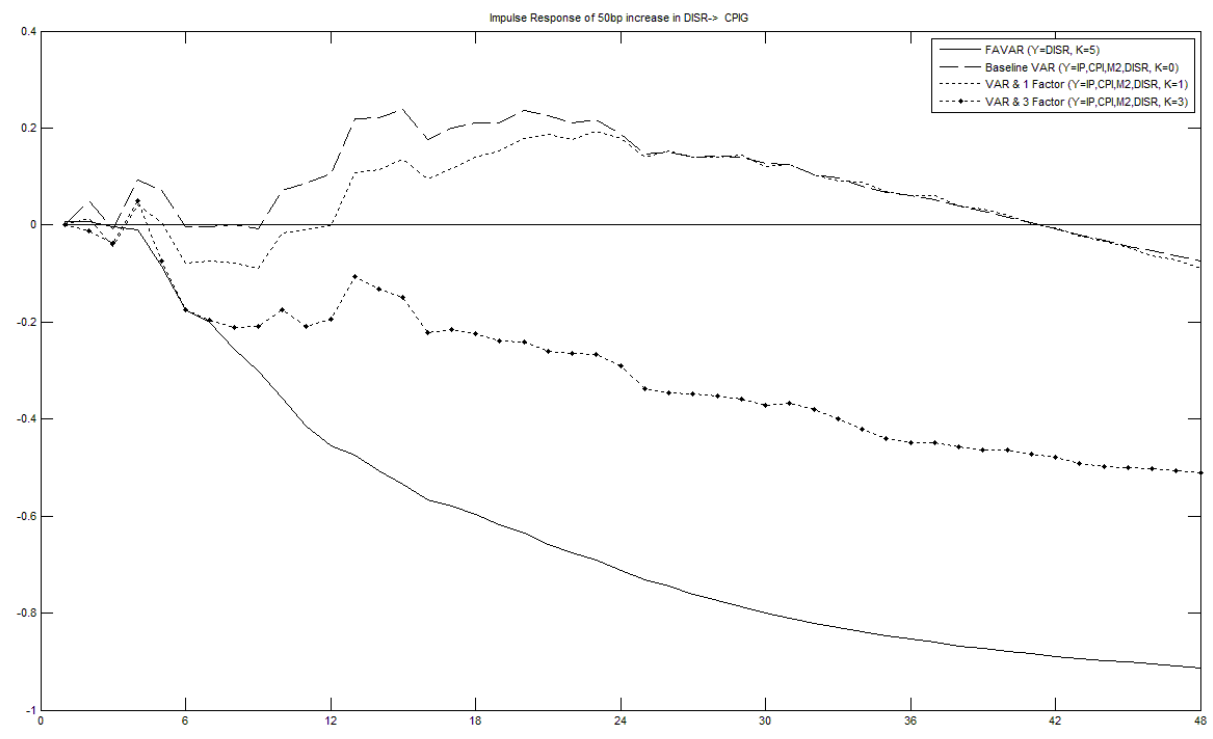

Figure 4.4 shows the responses of money supply (M2) when we shocked discount rate by positive 50bp. After the shock the benchmark FAVAR model suggest that money supply follows 
a steady declining trend up to 28 months and then starts increasing. This suggests that as interest rate increases, money supply decreases with the increase in interest rate. This result is consistent with the conventional transmission of money that an increase in interest rate causes money supply to decrease, furthermore this finding is inconsistent with the earlier findings that an increase in interest rate causes liquidity puzzle. The baseline VAR model shows that after a shock, money supply (M2) start declining after 12 months and then follows a declining trend, which shows weak existence of liquidity puzzle in Pakistan. If we include one factor and three factors in the VAR model results did not improves, the reason could be that we have included M2 in the category of fast variable in extracting factors. The other reason could be that monetary policy has contemporaneous effect on M2. However, the results with benchmark FAVAR model are much more consistent because M2 starts reviving after 30 months, while VAR model did not show any revival in M2 even after 48 months.

Figure 4.4: Impulse response of a 50bp shock in discount rate on M2

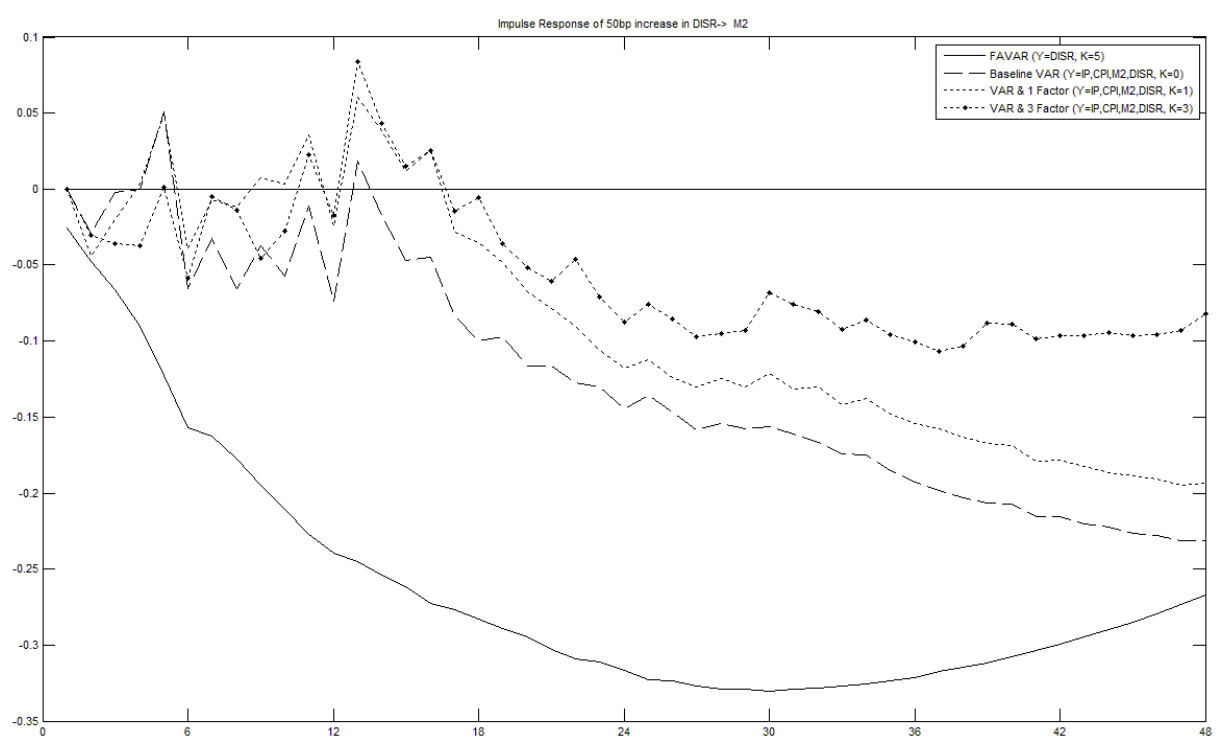




\section{Conclusion}

In this paper we analyzed the effects of monetary policy in Pakistan by using the FAVAR approach. Based on the above evidences we can say that in all four cases FAVAR model performed better than simple VAR model. FAVAR model provides more reliable results than a standard VAR model. In case of Pakistan, FAVAR model provides results which are consistent with the theory.

We got the evidence that benchmark FAVAR model explains the effects of monetary policy which are consistent with the theory and relatively better than baseline VAR model. Baseline VAR model shows the existence of price puzzle and liquidity puzzle in Pakistan, while benchmark FAVAR model did not provide any evidence of puzzles in Pakistan. The findings obtained using FAVAR model supports the effectiveness of interest rate channel in Pakistan. FAVAR model provides evidences that transmission of monetary policy shocks are faster in case of prices as compared to output in Pakistan.

We can conclude that benchmark FAVAR model shows results which are consistent with the theory about the effects of monetary policy on the economy as compared to VAR model. The transmission of monetary policy shock is faster in case of prices as compared to output in Pakistan. Monetary policy in Pakistan effects output in the short run but in the long run all effects of monetary impulses are transmitted to nominal variables i.e. money and prices. 


\section{References}

Agha, Asif Idress, Noor Ahmed, Yasir Ali Mubarik, and Hastam Shah. 2005. "Transmission Mechanism of Monetary Policy in Pakistan." SBP-Research Bulletin 1(1): 1-23.

Bagliano, Fabio C., and Carlo A. Favero. 1998. "Measuring Monetary Policy with VAR Models: An Evaluation.” European Economic Review 42(6): 1069-1112.

Bai, Jushan, and Serena Ng. 2002. "Determining the Number of Factors in Approximate Factor Models." Econometrica 70(1): 191-221.

Bernanke, Ben S., and Alan S. Blinder. 1992. "The Federal Funds Rate and the Channels of Monetary Transmission.” The American Economic Review 82(4): 901-921.

Bernanke, Ben S., and Jean Boivin. 2003. "Monetary Policy in a Data-Rich Environment." Journal of Monetary Economics 50(3): 525-546

Bernanke, Ben S., Jean Boivin, and Piotr S. Eliasz. 2005. "Measuring the Effects of Monetary Policy: A Factor-Augmented Vector Autoregressive (FAVAR) Approach." The Quarterly Journal of Economics 120(1): 387-422.

Blaes, Barno. 2009. "Money and Monetary Policy Transmission in the Euro Area: Evidence from FAVAR and VAR Approaches.” Deutsche Bundesbank Discussion Paper No. 18.

Breitung, Jorg, and Sandra Eickmeier. 2005. "Dynamic Factor Models.” Deutsche Bundesbank Discussion Paper No. 38.

Carvalho, Marina Delmondes, and Jose Luiz Rossi Junior. 2009. "Identification of Monetary Policy Shocks and its Effects: FAVAR Methodology for the Brazilian Economy." Brazilian Review of Econometrics 29( 2): 285-313

Christiano, Lawrence J., Martin Eichenbaum, and Charles L. Evans. 1999. "Monetary Policy Shocks: What have We Learned and to What End?" In Handbook of Macroeconomics, edited by John B. Taylor and Michael Woodford, 65-148. Amsterdam: Elsevier.

Hamilton, James D. 1994. Time Series Analysis. New Jersey: Princeton University Press.

Hussain, Karrar. 2009. "Monetary Policy Channels of Pakistan and Their Impact on Real GDP and Inflation." Center for International Development Graduate Student Working Paper No. 40.

Javid, Muhammad and Kashif Munir. 2011. "The Price Puzzle and Monetary Policy Transmission Mechanism in Pakistan: Structural Vector Autoregressive Approach", MPRA Paper No. 30670.

Kabundi, Alain, and Nonhlanhla Ngwenya. 2011. "Assessing Monetary Policy in South Africa in a Data-Rich Environment." South African Journal of Economics 79(1): 91-107. 
Khan, Mahmood-ul-Hassan. 2008. "Short Run effects of an Unanticipated Change in Monetary Policy: Interpreting Macroeconomic Dynamics in Pakistan”, SBP-Research Bulletin 4(1): $1-30$.

Kilian, Lutz. 1998. "Small-Sample Confidence Intervals for Impulse Response Functions." The Review of Economics and Statistics 80(2): 218-230

Lagana, Gianluca, and Andrew Mountford. 2005. "Measuring Monetary Policy in the U.K.: A Factor-Augmented Vector Autoregression Model Approach." The Manchester School 73(Special Edition): 77-98.

Lutkepohl, Helmut. 2005. New Introduction to Multiple Time Series Analysis. Berlin: SpringerVerlag.

Miyao, Ryuzo. 2002. "The Effects of Monetary Policy in Japan.” Journal of Money, Credit and Banking 34(2): 376-392.

Pakistan Bureau of Statistics. Monthly Bulletin of Statistics. Government of Pakistan (various issues).

Peersman, Gert, and Frank Smets. 2001. "The Monetary Transmission Mechanism in the Euro Area: More Evidence from VAR Analysis.” European Central Bank Working Paper No.91.

Senbet, Dawit. 2008. "Measuring the Impact and International Transmission of Monetary Policy: A factor-Augmented Vector Autoregressive (FAVAR) Approach." European Journal of Economics, Finance and Administrative Sciences 13: 121-143.

Shibamoto, Masahiko. 2007. "An Analysis Of Monetary Policy Shocks In Japan: A Factor Augmented Vector Autoregressive Approach." The Japanese Economic Review 58(4): 484-503.

Sims, Christopher A. 1980. "Macroeconomics and Reality.” Econometrica 48(1): 1-48. . 1992. "Interpreting the Macroeconomic Time Series Facts: The Effects of Monetary Policy." European Economic Review 36(5): 975-1000.

Soares, Rita. 2011. "Assessing Monetary Policy in the Euro Area: a Factor-Augmented VAR Approach.” Banco de Portugal Working Papers No. 11.

State Bank of Pakistan. Monthly Statistical Bulletin. State Bank of Pakistan (various issues).

Stock, James H., and Mark W. Watson. 2002. "Macroeconomic Forecasting Using Diffusion Indexes." Journal of Business \& Economic Statistics 20(2): 147-162.

Walsh, Carl E. 2010. Monetary Theory and Policy. 3rd ed. Cambridge: MIT Press. 


\section{Appendix A: Description of the Data}

The data listed below describe the complete description of the variable, define whether it is consider slow or fast moving variables, and the transformation applied to the series to make it stationary. Below are the numerical codes for the transformations performed on the data:

1: No transformation; 2: Log transformation; 3: First difference; 4: First difference of log

\begin{tabular}{|c|c|c|c|c|}
\hline S.No & Variable & Transformation & Fast/Slow & Detail of Variable \\
\hline & Outpu & & & \\
\hline 1 & IPI & 2 & SLOW & Industrial Production Index (SA) \\
\hline 2 & IPVP & 1 & SLOW & Production Index of Vegetable Products (SA) \\
\hline 3 & IPTB & 1 & SLOW & Production Index of Tea Blended (SA) \\
\hline 4 & IPJG & 1 & SLOW & Production Index of Jute Goods (SA) \\
\hline 5 & IPPB & 2 & SLOW & Production Index of Paper and Board (SA) (Base: 1999-2000) \\
\hline 6 & IPFL & 2 & SLOW & Production Index of Fertilizers (SA) \\
\hline 7 & IPAM & 4 & SLOW & Production Index of Auto-mobiles (SA) (Base: 1999-2000) \\
\hline 8 & PVG & 4 & SLOW & Production of Vegetable Ghee (SA) \\
\hline 9 & PSG & 1 & SLOW & Production of Sugar (NSA) \\
\hline 10 & PCGR & 1 & SLOW & Production of Cigarettes (SA) \\
\hline 11 & PCY & 4 & SLOW & Production of Cotton Yarn (SA) \\
\hline 12 & PCC & 4 & SLOW & Production of Cotton Cloth (SA) \\
\hline 13 & PPR & 4 & SLOW & Production of Paper (SA) \\
\hline 14 & PPB & 4 & SLOW & Production of Paper Board (SA) \\
\hline 15 & PSDA & 1 & SLOW & Production of Soda Ash (SA) \\
\hline 16 & PCS & 4 & SLOW & Production of Caustic Soda (SA) \\
\hline 17 & PSUA & 4 & SLOW & Production of Sulphuric Acid (SA) \\
\hline 18 & PCHG & 1 & SLOW & Production of Chlorine Gas (SA) \\
\hline 19 & PUR & 1 & SLOW & Production of Urea (SA) \\
\hline 20 & PSP & 1 & SLOW & Production of Super Phosphate (NSA) \\
\hline 21 & PAN & 1 & SLOW & Production of Ammonium Nitrate (SA) \\
\hline 22 & PNP & 1 & SLOW & Production of Nitro Phosphate (SA) \\
\hline 23 & PCTT & 4 & SLOW & Production of Cycles Tyres and Tubes (SA) \\
\hline 24 & PMTT & 4 & SLOW & Production of Motor Tyre and Tubes (SA) \\
\hline 25 & PCMN & 4 & SLOW & Production of Cement (SA) \\
\hline 26 & PPI & 1 & SLOW & Production of Pig Iron (SA) \\
\hline 27 & PTR & 1 & SLOW & Production of Tractors (SA) \\
\hline 28 & PBC & 1 & SLOW & Production of Bicycle (SA) \\
\hline
\end{tabular}




$\begin{array}{ll}29 & \text { PSS } \\ 30 & \text { PGPS } \\ 31 & \text { PLST } \\ 32 & \text { PRST } \\ 33 & \text { PCOL } \\ 34 & \text { PCHCL } \\ 35 & \text { PCHM } \\ 36 & \text { PCRO } \\ 37 & \text { PNGS } \\ 38 & \text { PELC }\end{array}$

Prices

$\begin{array}{ll}39 & \text { CPIG } \\ 40 & \text { CPIFBT } \\ 41 & \text { CPIAPF } \\ 42 & \text { CPIHR } \\ 43 & \text { CPIFL } \\ 44 & \text { CPIHFFE } \\ 45 & \text { CPITC } \\ 46 & \text { CPIRE } \\ 47 & \text { CPICLPA } \\ 48 & \text { WPIG } \\ 49 & \text { WPIF } \\ 50 & \text { WPIRM } \\ 51 & \text { WPIFLL } \\ 52 & \text { WPIM } \\ 53 & \text { WPIBM }\end{array}$

4

Capital Market

$\begin{array}{ll}54 & \text { GIG } \\ 55 & \text { GICOT } \\ 56 & \text { GITS } \\ 57 & \text { GITWC } \\ 58 & \text { GIOT } \\ 59 & \text { GICOP } \\ 60 & \text { GIE }\end{array}$

$\begin{array}{ll}\text { SLOW } & \text { Production of Silica Sand (SA) } \\ \text { SLOW } & \text { Production of Gypsum (SA) } \\ \text { SLOW } & \text { Production of Lime Stone (SA) } \\ \text { SLOW } & \text { Production of Rock Salt (SA) } \\ \text { SLOW } & \text { Production of Coal (SA) } \\ \text { SLOW } & \text { Production of China Clay (SA) } \\ \text { SLOW } & \text { Production of Chromite (SA) } \\ \text { SLOW } & \text { Production of Crude Oil (SA) } \\ \text { SLOW } & \text { Production of Natural Gas (SA) } \\ \text { SLOW } & \text { Production of Electricity (SA) }\end{array}$

SLOW CPI: General (SA)

SLOW CPI: Food Beverages and Tobacco (SA) (Base:2000-2001)

SLOW CPI: Apparel textile and Footwear (SA)

SLOW CPI: House Rent (SA)

SLOW CPI: Fuel and Lighting (SA)

SLOW CPI: Household Furniture and Equipment (SA) (Base:2000-2001)

SLOW CPI: Transportation and Communication (SA) (Base:2000-2001)

SLOW CPI: Recreation and Entertainment (SA) (Base:2000-2001)

SLOW CPI: Cleaning Laundry and Personal Appearance (SA)

SLOW WPI: General (SA)

SLOW WPI: Food (SA)

SLOW WPI: Raw Material (SA)

SLOW WPI: Fuel, Lighting and Lubricants (SA)

SLOW WPI: Manufacturers (SA)

SLOW WPI: Building Materials (SA)

\author{
FAST SBGI: General (SA) \\ FAST SBGI: Cotton and Other Textiles (SA) \\ FAST SBGI: Textile Spinning (SA) \\ FAST SBGI: Textile Weaving and Composite (SA) (Base:2000-2001) \\ FAST SBGI: Other textiles (SA) \\ FAST SBGI: Chemical and other Pharmaceuticals(SA) (Base:2000- \\ FAST SBGI: Engineering (SA)
}




\begin{tabular}{ll}
61 & GIAA \\
62 & GICEG \\
63 & GISA \\
64 & GIPB \\
65 & GIC \\
66 & GIFE \\
67 & GITC \\
68 & GIBOFI \\
69 & GIBIC \\
70 & GIMD \\
71 & GILC \\
72 & GII \\
73 & GIMQ \\
74 & GIJ \\
75 & GIFA \\
76 & GIGC \\
77 & GIVA \\
78 & GIO \\
79 & SIG \\
80 & SICOT \\
81 & SICOP \\
82 & SIE \\
83 & SIAA \\
84 & SICEG \\
85 & SISA \\
86 & SIPB \\
87 & SIC \\
88 & SIFE \\
89 & SITC \\
90 & SIBOFI \\
91 & SIMQ \\
93 & Interest Rate \\
\hline 2 DISR \\
\hline 6
\end{tabular}

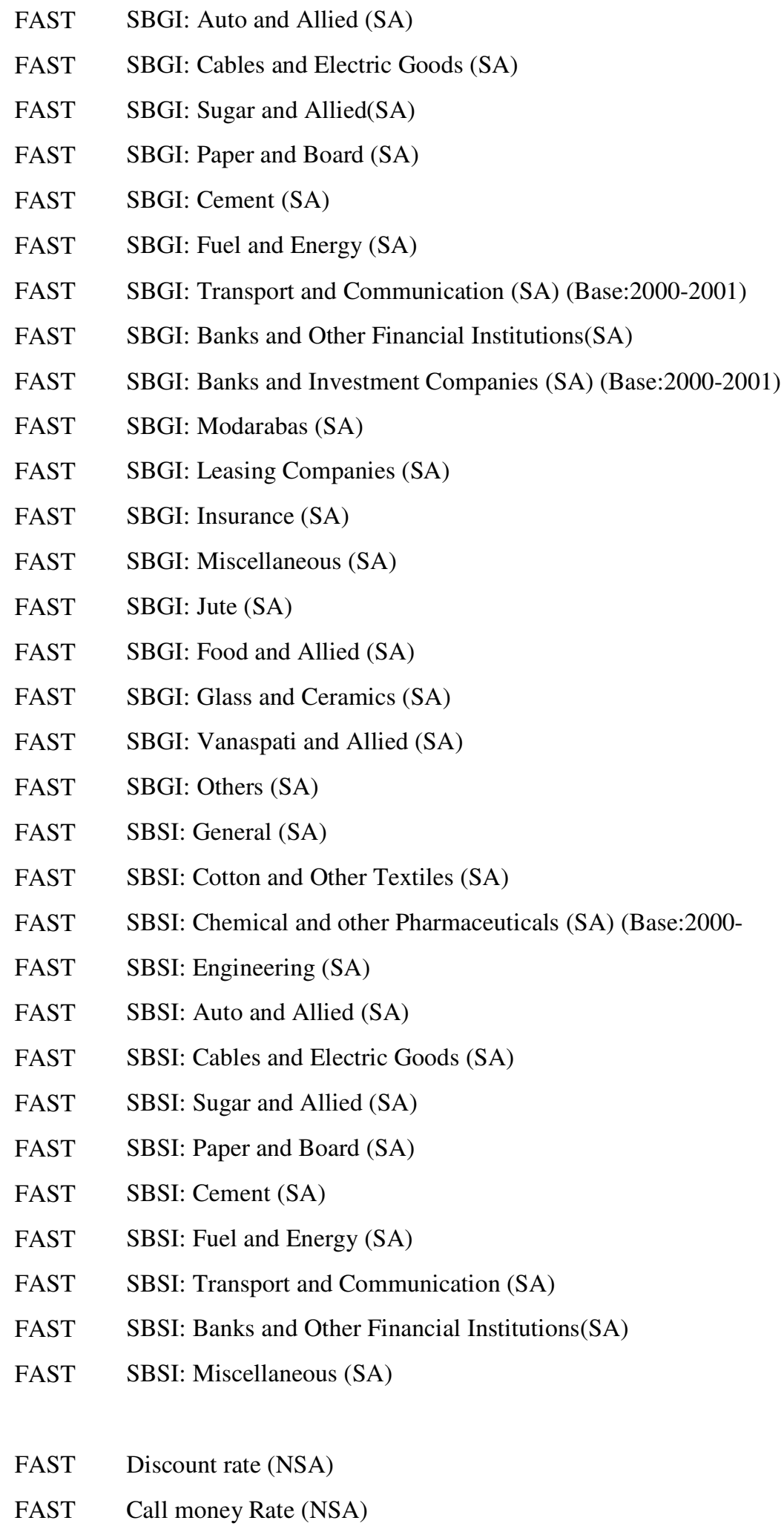




\begin{tabular}{|c|c|c|c|c|}
\hline 94 & GTB6m & 2 & FAST & 6-month Govt. Treasury Bill Rate (NSA) \\
\hline \multirow[t]{2}{*}{95} & GBY & 2 & FAST & Govt. Bond Yield (NSA) \\
\hline & Money \&C & & & \\
\hline 96 & M0 & 4 & FAST & M0 : Reserve Money (SA) \\
\hline 97 & M1 & 4 & FAST & M1 : Narrow Money (SA) \\
\hline 98 & M2 & 4 & FAST & M2 : Broad Money (SA) \\
\hline 99 & CPSE & 4 & FAST & Credit to Public Sector Enterprises (SA) \\
\hline \multirow[t]{2}{*}{100} & CPS & 4 & FAST & Credit to Private Sector (SA) \\
\hline & External S & & & \\
\hline 101 & EXRUSA & 4 & FAST & Exchange Rate USA, Rs/\$ (NSA) \\
\hline 102 & NEER & 4 & FAST & Nominal Effective Exchange Rate (NSA) \\
\hline 103 & REER & 1 & FAST & Real Effective Exchange Rate (NSA) \\
\hline 104 & RSDRH & 2 & FAST & Reserve: SDR Holding (SA) \\
\hline 105 & RFEX & 4 & FAST & Reserve: Foreign Exchange (SA) \\
\hline 106 & RGLD & 4 & FAST & Reserve: Gold (SA) \\
\hline 107 & ITI & 4 & SLOW & Total Imports (SA) \\
\hline 108 & ICNM & 4 & SLOW & Imports of Consumer Goods (SA) \\
\hline 109 & IRMCNG & 2 & SLOW & Imports of Raw material Consumer Goods (SA) \\
\hline 110 & IRMCPG & 4 & SLOW & Imports of Raw material Capital Goods (SA) \\
\hline 111 & ICPG & 4 & SLOW & Imports of Capital Goods (SA) \\
\hline 112 & ETE & 2 & SLOW & Total Exports (SA) \\
\hline 113 & EPRC & 2 & SLOW & Export of Primary Commodities (SA) \\
\hline 114 & ESM & 4 & SLOW & Export of Semi Manufactures (SA) \\
\hline 115 & EMG & 2 & SLOW & Export of Manufactured Goods (SA) \\
\hline
\end{tabular}

